\title{
Анализ развития экономики различных регионов России и их перспективы
}

\author{
Петр Арефьев* , Алина Румянцева \\ Финансовый университет при Правительстве Российской Федерации, Москва, Россия
}

\author{
Информация о статье \\ Поступила в редакиию: \\ 21.12.2018 \\ Принята \\ к опубликованию: \\ 14.08.2019 \\ УДК 338.001 .36 \\ JEL R58
}

\section{Ключевье слова:}

анализ, экономика региона, совершенствование, развитие, Ростовская область, Краснодарский край

\section{Keywords:}

analysis, regional economy, improvement, development, Rostov region, the Krasnodar Territory

\begin{abstract}
Аннотация
Сочиально-экономическая ситуачия в России является довольно сложной. Хотя переход в положительную фазу роста приобрел продолжение, качественные и количественные характеристики данного повышения нельзя признать удовлетворительными. Однако определенные показатели, которые отрицательно характеризуют экономическую динами$\kappa y$, не всегда говорят о негативных трендах. В статье проведен анализ развития экономики различных регионов России (в частности, Ростовская область и Краснодарский край). Выделень перспективы развития экономики в рассматриваемых субъектах Российской Федерации. Анализ экономики Ростовской области и Краснодарского края показал, что достигнуты соответствующие успехи и есть предпосылки для устойчивого экономического повышения.
\end{abstract}

\section{Analysis of Economic Development in Various Regions} of Russia and Their Prospects

Petr Arefiev, Alina Rumyantseva

\section{Abstract}

The socio-economic situation in Russia is quite complicated. Although the transition to a positive growth phase is in progress, qualitative and quantitative characteristics of this improvement cannot be considered satisfactory. However, some indicators that characterize the economic dynamics negatively do not always indicate the negative trends. The paper describes the analysis of the economies development in various regions of Russia (in particular, the Rostov region and the Krasnodar Territory). The prospects for the economies development in the mentioned constituent entities of the Russian Federation were stated in the paper. The investigation identified the prospects for the Krasnodar Territory economy development, such as securing and increasing the competitive advantages in the traditional industries to create a sustainable model of improvement; slight increasing of the human capital; implementing a limited number of the long-term priority programs and projects that realize the comparative advantages of the social sphere and economy; insignificant increasing of the investment climate; developing the

\footnotetext{
* Автор для связи: arefyev2001@ mail.ru
}

DOI: https://dx.doi.org/10.24866/2311-2271/2019-4/17-22 
conditions for the spatial improvement; improving the institutional environment, which facilitates the balanced sustainable development; increasing the integration processes in international and interregional socio-economic space. The economies analysis in the Rostov region and the Krasnodar Territory showed that the appropriate progress had been made and there were the prerequisites for the sustainable economic improvement.

В 2018 г. глобальная экономика устойчиво росла приемлемым темпом порядка 3,7\%. Более того, данный рост продолжается практически 10 лет, что нечасто встречалось в нынешней экономической истории развитых государств.

Но преобладающая тема экономико-политических дискуссий политиков и экспертов ведущих государств - это неустойчивость экономического роста и планирование будущего кризиса. Причины данных ожиданий связывают с самим фактом продолжительного роста: он не бесконечен. Имеется в виду не глобальный структурный кризис, а обычный циклический - Next Normalsize Recession (К. Рогофф) [1].

Социально-экономическая ситуация в нашей стране является попрежнему сложной. В дискуссиях об экономической политике предлагаются довольно противоречивые рекомендации. В табл. 1 представлены основные характеристики текущей ситуации.

Таблииа 1

Основные экономические показатели Российской Федерации за 2007-2018 22.

\begin{tabular}{|l|c|c|c|c|c|c|c|c|c|c|c|c|c|c|c|c|c|}
\hline \multicolumn{1}{|c}{$\mathbf{1}$} & $\mathbf{2 0 0 7}$ & $\mathbf{2 0 0 8}$ & $\mathbf{2 0 0 9}$ & $\mathbf{2 0 1 0}$ & $\mathbf{2 0 1 1}$ & $\mathbf{2 0 1 2}$ & $\mathbf{2 0 1 3}$ & $\mathbf{2 0 1 4}$ & $\mathbf{2 0 1 5}$ & $\mathbf{2 0 1 6}$ & $\mathbf{2 0 1 7}$ & $\mathbf{2 0 1 8}$ \\
\hline & $\mathbf{2}$ & $\mathbf{3}$ & $\mathbf{4}$ & $\mathbf{5}$ & $\mathbf{6}$ & $\mathbf{7}$ & $\mathbf{8}$ & $\mathbf{9}$ & $\mathbf{1 0}$ & $\mathbf{1 1}$ & $\mathbf{1 2}$ & $\mathbf{1 3}$ \\
\hline Макропоказатели (темпы прироста физического объема, \% к предыдущему году (если иное не указано)) \\
\hline ВВП & 8,5 & 5,2 & $-7,8$ & 4,5 & 4,3 & 3,7 & 1,8 & 0,7 & $-2,5$ & 0,3 & 1,6 & 2,3 \\
\hline Промышленность & 6,8 & 0,6 & $-10,7$ & 7,3 & 5 & 3,4 & 0,4 & 1,7 & $-0,8$ & 2,2 & 2,1 & 2,9 \\
\hline Сельское хозяйство & 3,3 & 10,8 & 1,4 & $-11,3$ & 23 & $-4,8$ & 5,8 & 3,5 & 2,6 & 4,8 & 3,1 & $-0,6$ \\
\hline Строительство & 18,2 & 12,8 & $-13,2$ & 5 & 5,1 & 2,5 & 0,1 & $-2,3$ & $-3,9$ & $-2,1$ & $-1,2$ & 5,3 \\
\hline Оптовая торговля & 9,5 & 5,4 & 2 & 3 & 4,4 & 3,6 & 0,7 & 3,9 & $-5,5$ & 3,1 & 5,7 & 2,4 \\
\hline Розничная торговля & 16,1 & 13,7 & $-5,1$ & 6,5 & 7,1 & 6,3 & 3,9 & 2,7 & -10 & $-4,6$ & 1,3 & 2,6 \\
\hline $\begin{array}{l}\text { Конечное потребление до- } \\
\text { машних хозяйств }\end{array}$ & 14,3 & 10,6 & $-5,1$ & 5,5 & 6,8 & 7,9 & 5,2 & 2 & $-9,4$ & $-1,9$ & 3,2 & 2,2 \\
\hline $\begin{array}{l}\text { Инвестиции в основной } \\
\text { капитал }\end{array}$ & 23,8 & 9,5 & $-13,5$ & 6,3 & 10,8 & 6,8 & 0,8 & $-1,5$ & $-10,1$ & $-0,2$ & 4,8 & 4,3 \\
\hline Доля оплаты труда в ВВП, \% & 46,7 & 47,4 & 52,6 & 49,6 & 43,8 & 44,3 & 46,2 & 47,2 & 46,5 & 47,3 & 47,1 & 45,7 \\
\hline $\begin{array}{l}\text { Доля прибыли и смешанных } \\
\text { доходов в ВВП, \% }\end{array}$ & 34,1 & 32,7 & 30,8 & 32,6 & 41,8 & 41,4 & 40 & 38,9 & 42,3 & 41,7 & 42,1 & 42,9 \\
\hline $\begin{array}{l}\text { Прямые иностранные инве- } \\
\text { стиции в РФ, млрд долл. }\end{array}$ & 55,9 & 74,8 & 36,6 & 43,2 & 55,1 & 50,6 & 69,2 & 22 & 6,9 & 32,5 & 28,6 & 4,8 \\
\hline $\begin{array}{l}\text { Прямые иностранные инве- } \\
\text { стиции в РФ, кроме банков, } \\
\text { \% }\end{array}$ & 49,4 & 64,9 & 29,9 & 38 & 50 & 42,8 & 60,1 & 17,6 & 6,3 & 30,9 & 27,1 & 1,9 \\
\hline
\end{tabular}

Источник: составлено авторами по [2]

В табл. 1 можно наблюдать экономический рост, но его темп значительно отстает от среднемирового.

Для анализа экономики регионов России были выбраны Ростовская область и Краснодарский край.

Валовой региональный продукт Ростовской области в 2018 г. равен почти 1 трлн 400 млрд руб. (в прошлом отчетном периоде - 1344,0 млрд руб.), что соответствует приросту экономики относительно 2017 г. на 1,3\% (рост ВВП в России в 2018 г. - на 2,3\%). 
По определенным показателям, как и в прошлые годы, рассматриваемый субъект Российской Федерации опережает среднероссийские темпы совершенствования, что свидетельствует об ее статусе лидера. Индекс промышленного производства в регионе равен 109,7\% (102,9\% - России), остались темпы по вводу жилья на уровне 2017 г. (100,6\% - Ростовская область, 95,1\% - Российская Федерация).

Положительная тенденция создана на потребительском рынке. Повышение оборота розничной торговли в текущем году относительно прошлого равно $103,1 \%$, общественного питания - $105,5 \%$.

Окончание строительства объектов инженерной, спортивной и транспортной инфраструктуры к Чемпионату мира по футболу - 2018 и эффект большой базы 2017 г. оказали отрицательное влияние на результаты строительной области (на 33,5\% меньше чем в 2017 г.). Также, несмотря на довольно хорошие итоги работы аграрного сектора, засуха и эпидемии птичьего гриппа не позволили выйти региону на первоначально ожидаемые темпы роста. Значительная удельная доля данных отраслей в экономике субъекта оказала существенное влияние на темп роста ВРП в 2018 г. (+1,3 \%). В 2017 г. темп роста ВРП области был равен 102,9\%.

По результатам текущего года объем продукции сельского хозяйства региона уменьшился на 9,6\% (в хозяйствах всех категорий, учитывая индексдефлятор), что связано с нижеуказанными причинами.

1. Неблагоприятные сезонно-климатические условия и сложная эпизоотическая ситуация.

2. Рекордные итоги прошлого года (13,7 млн тонн зерна в исходно оприходованном весе - 2017 г.; 11.1 млн тонн - 2018 г.) создали эффект, который принято называть «большая база».

Однако, на данном фоне несколько районов региона сохранили и даже увеличили урожайность сельскохозяйственных культур относительно прошлого года. В области животноводства выпущено продукции на уровне прошлого года, кроме яиц, производство которых уменьшилось на 10\%. Положительных итогов достигли компания рыбохозяйственного комплекса: повышения производства переработанной и товарной рыбы повысилось на $10 \%$, вылов биоресурсов на $34,3 \%$.

Для повышения производительности труда на средних и крупных компаниях базовых несырьевых отраслей экономики рассматриваемого региона были разработаны два региональных проекта «Системные меры по росту производительности труда» и «Адресная поддержка роста производительности труда в компаниях Ростовской области».

Продолжается деятельность по совершенствованию конкуренции в анализируемом субъекте. Исполнены требования Стандарта совершенствования конкуренции, подготовлен и согласован Перечень основных и социальнозначимых рынков области, а также дорожная карта по содействию совершенствованию конкуренции, совершается мониторинг состояния и совершенствования конкурентной среды в субъекте.

Выполнение консолидированного бюджета региона за 2018 г. по доходам равно 217,3 млрд руб., по расходам - 209,4 млрд руб. Обеспечен профицит в размере 7,9 млрд руб. В бюджет региона обеспечено поступление 178,4 млрд рублей собственных неналоговых и налоговых доходов с повышением к 2018 г. на 21,8 млрд руб. или на 13,9\%. 
Приоритет бюджетной политики региона в области расходов это обеспечение жителями услугами отраслей социальной области и некоторых категорий населения выплатами и льготами. На данные цели было направлено 142,8 млрд руб., что равно $68,2 \%$ всех расходов консолидированного бюджета. По результатам 2018 г. областной и местные бюджеты были сбалансированы. Просроченной кредиторской задолженности нет [3].

Результаты анализа экономики Ростовской области показывают, что достигнуты соответствующие успехи и есть предпосылки для устойчивого экономического повышения.

Основная задача совершенствования экономики рассматриваемого региона - это рост платежеспособного спроса при помощи обеспечения экономического роста; роста ВРП путем ввода новых технологий, повышения производительности труда, роста эффективности производства, диверсификации производства и развития региональной нормативной законодательной базы.

Для будущего экономического совершенствования области необходимо исполнение следующих главных направлений и целей: увеличение конкурентоспособности экономики региона, пространственное совершенствование области, рост уровня и качества жизни жителей Ростовской области.

Далее следует рассмотреть результаты анализа Краснодарского края. Информация за 2018 г. говорит о довольно стабильной социальноэкономической ситуации в регионе. Большая часть отраслей экономики показывают позитивную тенденцию. Общественное питание, розничная торговля и сфера платных услуг жителям продемонстрировали более существенные темпы роста, чем в прошлом году.

Однако, уменьшение объёмов сельскохозяйственного производства и исполненных строительных работ не позволило провести оценку роста ВРП региона более 101,9\% (на фоне 103,1\% в 2017 г.).

Повышение промышленного производства равно104,2\% (104,4\% в 2017 г.). Сдерживающий фактор - это снижение объёмов нефтепереработки (на 9,7\%) и производства пищевых продуктов (на 6,8\%), на долю которых приходится $32 \%$ и $25 \%$ отгрузки промышленных товаров соответственно.

Тенденция в сельском хозяйстве составила 96,0\%. Благодаря засухе не был получен достойный урожай зерна, сахарной свёклы и подсолнечника. Однако удалось добиться значительного повышения производства ягод и плодов, картофеля, винограда, молока.

Объём исполненных работ в строительстве уменьшился на $11,5 \%$ относительно 13,5\% роста, который был в 2017 г., что связано со строительством Крымского моста. Следует обратить внимание и на снижение в жилищном строительстве. Ввод в действие жилых домов уменьшился на 7,1\% (в прошлом году рост составил 5\%). В первую очередь, это обусловлено снижением на $18 \%$ ввода домов массовой застройки в г. Краснодаре, что можно объяснить ужесточением контроля над строительством многоквартирного жилья согласно градостроительным планам и перспективному планированию города.

В хранении и транспортировке тенденция объёмов услуг в сопоставимых ценах равна 103,6 \%. Повышение грузооборота обеспечено автомобильным, железнодорожным и трубопроводным транспортом, увеличились объёмы перевалки грузов в морских портах. Повысился пассажиропоток на железнодорожном транспорте и через аэропорты региона. 
Индекс промышленного производства по результатам текущего года равен 104,2\%. Общий объём инвестиций в основной капитал равен 278,6 млрд руб. Инвестиционные вливания в экономику со стороны крупных и средних компаний уменьшились на $10,0 \%$ и стали равны 223,9 млрд руб. Объём производства продукции сельского хозяйства равен 359,3 млрд руб.

По результатам 2018 г. доходы консолидированного бюджета региона (учитывая безвозмездные поступления) равны 316 238,7 млн руб., или 106,5\% относительно 2017 г.

Налоговых и неналоговых доходов мобилизовано 275 594,9 млн руб. Темп роста составил $109,1 \%$. Данная динамика поступлений обусловлена мобилизацией платежей по нижеуказанным главным доходным источникам:

- налог на доходы физических лиц - 87 521,5 млн руб. (повышение на $1,9 \%$

- налог на прибыль предприятий - 59 190,4 млн руб. (повышение на $14,0 \%)$

- акцизы - 24 712,6 млн руб. (повышение на 0,7\%);

- налог на имущество предприятий - 41 131,7 млн руб. (повышение на $25,6 \%)$

- налог, взимаемый в связи с использованием упрощённой системы налогообложения - 19 439,0 млн руб. (повышение на 23,6\%).

Расходы консолидированного бюджета региона равны 300 332,7 млн руб., темп роста - 107,5\% относительно 2017 г. [4]. Удельная доля расходов по отраслям представлена на рис. 2.

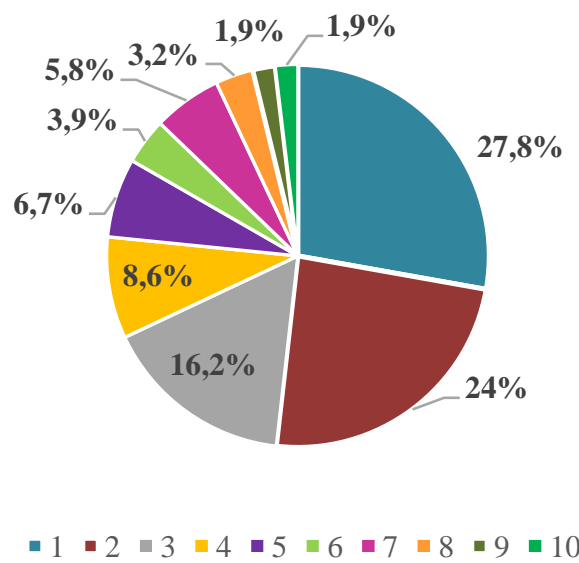

Рuc. 2. Удельная доля расходов по отраслям

Примечание: 1 - образование; 2 - социальная политика; 3 - национальная экономика; 4 - здравоохранение; 5 - общегосударственные вопросы; 6 - культура, кинематография; 7 - жилищнокоммунальное хозяйство; 8 - физическая культура и спорт; 9 - обслуживание государственного долга; 10 - прочие отрасли

Источник: составлено авторами по [2]

В результате исследования выявлены следующие перспективы развития экономики Краснодарского края:

- закрепление и увеличение конкурентных преимуществ в традиционных отраслях для создания устойчивой модели совершенствования, которая позволит обеспечить несущественное уменьшение разрыва в конкурентоспо- 
собности большей части отраслей экономики региона от уровня лучших зарубежных производителей, что, в свою очередь, приведет к несущественному преобразованию экономической структуры субъекта;

- незначительное повышение человеческого капитала;

- осуществление ограниченного числа долгосрочных приоритетных программ и проектов, которые реализуют сравнительные преимущества социальной сферы и экономики;

- несущественное увеличение инвестиционного климата;

- создание условий пространственного совершенствования;

- совершенствование институциональной среды, которая способствует сбалансированному устойчивому совершенствованию;

- увеличение интеграционных процессов в международное и межрегиональное социально-экономическое пространство.

Таким образом, был проведен анализ обшей экономической ситуации в стране в целом, а также в Ростовской области и в Краснодарском крае, в частности. Были определены перспективы развития экономики в рассматриваемых субъектах Российской Федерации.

\section{Список источников / References}

1. Рогофф К. Бюджетная скованность Центробанков. Прожект Синдикат. 4 января 2019. [Rogoff K. Bjudzhetnaja skovannost' centrobankov // Project Syndicate. 4 January 2019]. Available at: https://www.project-syndicate.org/commentary/countercyclical-fiscal-policyno-cure-in-next-recession-by-kenneth-rogoff-2019-01?barrier=accesspaylog (accessed: 06.11.2019).

2. Официальный сайт: Федеральная служба государственной статистики. [Oficial'nyj sajt: Federal'naja sluzhba gosudarstvennoj statistiki]. Available at: https://www.gks.ru (accessed: 06.11.2019).

3. Официальный сайт: Министерство экономического развития Ростовской области. [Oficial'nyj sajt: Ministerstvo jekonomicheskogo razvitija Rostovskoj oblasti]. Available at: https://mineconomikiro.donland.ru (accessed: 06.11.2019).

4. Официальный сайт: Министерство экономики Краснодарского края. [Oficial'nyj sajt: Ministerstvo jekonomiki Krasnodarskogo kraja]. Available at: https://economy.krasnodar.ru (accessed: 06.11.2019).

\section{Сведения об авторах / About authors}

Арефьев Петр Владимирович, кандидат экономических наук, доцент, Финансовый университет при Правительстве Российской Федерации. 125993 Россия, г. Москва, ГСП-3, Ленинградский проспект, 49. E-mail: arefyev2001@ mail.ru

Petr V. Arefiev, Candidate of Economic Sciences, Associate Professor, Financial University under the Government of the Russian Federation. 49 Leningradsky Prospect, GSP-3, Moscow, Russia 125993.

E-mail: arefyev2001@mail.ru

Румянцева Алина Евгеньевна, студент, Финансовый университета при Правительстве Российской Федерации. 125993 Россия, г. Москва, ГСП-3, Ленинградский проспект, д. 49.

E-mail: erum1975@yandex.ru

Alina E. Rumyantseva, Student, Financial University under the Government of the Russian Federation.

49 Leningradsky Prospect, GSP-3, Moscow, Russia 125993. E-mail: erum1975@yandex.ru 